\title{
THE FORMATION OF THE OOTHECA OF A CHINESE MANTIS, HIERODULA SAUSSURII.
}

\author{
By J. C. Kershaw.
}

This large and handsome Mantis, bright green in its wet season or summer dress, various shades of brown in dry season, appears almost invariably to construct its very complex ootheca during the night, or very early morning. They pair like locusts, the male clasping the female round the thorax with his forelegs. They seem to copulate two or three times for about three hours at a time on separate occasions during two or three days. After the last coupling, unless the male is very smart in disengaging himself, he is often caught and killed by the female, though he is not much smaller, being some two and one-half inches from the face to the tip of the abdomen. Once fertilized, the female makes four or more oothecæ at intervals of about twenty days, the first being made about nine days after the last coupling. It would seem, therefore, that the female is fertilized once for all. The oothecæ are made chiefly during September to January inclusive, i. e., mostly during the dry season or winter. They are constructed on tree-trunks, twigs, walls, boulders and many other objects. The female is fond, however, of getting a more or less vertical support against which to make the preliminary plates, besides a horizontal foundation for the floor of the ootheca. The oothecæ are fixed in all positions, both vertical and horizontal, but the female seems specially fond of working with her back downwards. Before commencing an egg-case, the Mantis is restless and keeps turning the abdomen (which is much swollen and heavy) laterally and letting it hang for some time first one side and then the other. She also walks slowly up and down, feeling various surfaces with the tip of the abdomen. Whilst making the ootheca the female grasps the twig or bark with her forelegs. The wings are closed and the tips held high above the back of the abdomen, out of the way. The cercx are incessantly used to gauge the outer dimensions of the case. One of ordinary size, say about an inch in length and containing perhaps two dozen egg chambers, takes two to three hours to com- 
plete. At first the colleterial matter is whitish, but is soon variegated with bluish and greenish; it afterwards turns brown, but for some hours it remains in a more or less soft condition. In a few days it becomes extremely hard and tough.

The oothecæ are parasitized badly by a species of Dermestes, whose larvæ destroy the whole interior. Besides this beetle, a small Hymenopteron (Podagrion sp.) and the larva of a moth are parasitic on Mantis eggs, and emerge by small round holes through various parts of the ootheca; but these parasites do not destroy the plates of the egg chambers, as the beetle larva does. At least seventy to eighty per cent. of the oothecæ are parasitized, and this is judging from several hundred egg-cases collected for some years over a very wide area.

The female has two sets of large colleterial glands, one set each side of the abdomen. They consist of long tubes, narrowing gradually to a blind end, and at the base uniting into one large, short duct; the two ducts of each set of tubes join in one large and very short duct opening into the dorsal side of the vagina. Close behind this duct are two small branching glands, also joining in a short, common duct. There is a large, globulate spermatheca.

The ootheca consists of two parallel rows of egg chambers (a row each side of the longitudinal center of the case, with about a dozen chambers in each row), the chambers of one side being half the depth of a chamber behind (or in front of) the chambers of the other side. Each chamber is formed by two plates, each plate forming the back of one chamber and the front of another. The plates overlap, a little beyond the vertical center, first one side and then the other, and are cemented together along this joint. At the top each plate expands laterally to the full width of the flaps, and a little higher still the cementing ceases and the flaps become free from each other. The flaps may be considered thin and flexible continuations of the plates, and are bent forwards at a rather sharp angle to form a protecting roof over the exits of the chambers. The sides or flanges of the chambers are formed by strips cemented around the outer edges of the plates. Outside the egg chambers is another covering or casing, formed by broad strips twisted at the top so as to attach to the base of the flaps; these strips overlap (or are received into) each other, and at the bottom are also twisted 
and broadened into feet, which also overlap one another and are cemented to whatever foundation the ootheca is being constructed upon. The feet of the egg plates (which also slightly overlap each other) rest upon and are cemented to the feet of the coverstrips thus an air-space is left between the mass of egg chambers and the outer casing formed by the coverstrips. This air-space is, however, often roughly divided into cells by the ragged edges of the egg plates projecting between the flanges of the chambers, as indicated by dotted lines at 22, Fig. 5, Pl. 1. The coverstrips at the two ends of the ootheca are brought together and overlapped very much like the planking at the bows and stern of a boat. There are usually two or three roughly-formed smaller chambers, without eggs, at both ends of the egg-case. Those at the back end (increasing in size) form the foundation or support for the egg chambers proper; those at the front end (decreasing in size) bring the chambers gradually small enough to be closed by a single central plate (Cp, Fig. 2, Pl. 1).

In brief, the ootheca consists of an outer casing formed of overlapping coverstrips, within which are two parallel rows of egg chambers, so cemented together as to form a hard, tough mass.

The process of construction is somewhat as follows: A small plate (B, Fig. 2, Pl. 1) forming the back end of the ootheca having been cemented to the bark or other object, an outer coverstrip (CVS, Fig. 2, P1. 1) is attached each side. Two or three more small but increasing plates are added, with their respective coverstrips, so that the feet of the latter now project forward some distance along the bark, and form a foundation for the feet of the egg plates. An egg plate (EP, Fig. 2, PI. 1) is now formed against the last small plate (E, Fig. 2, Pl. 1), a flap (FL, Figs. 1 and 3, P1. 1) is added, an outer coverstrip (CVS, Fig. 2, P1. 1) attached, a closing membrane (CM, Fig. 1, P1. 1) stuck on, and finally the eggs laid in the numbered order. After the eggs are laid and before the next egg plate covers them they are, nevertheless, covered with a thin film of colleterial matter, extending to the top of the closing membrane. 'The superabundant colleterial matter also becomes (by mutual pressure of eggs and egg plates) squeezed into the interstices between the eggs, forming little ridges or partitions between the eggs, rather deep near the outer 
edges or flanges of the egg plates, but altogether working out and disappearing in the central part of the egg plate, thus leaving a passageway for the nymphs from the lower eggs. The hollows where the eggs lie and the ridges between them are shown on th: left-hand egg plate in Fig. 7, Pl. 2.

The insect next makes the egg plate and its concomitant parts for the egg chamber of the opposite row, and lays the eggs thereon. It next forms another egg plate over the eggs first laid, and thereafter adds a chamber alternately to each row until the whole batch of eggs is laid; then a few small, rough chambers decreasing in size and without eggs are added, and finally the ootheca is closed by one small central plate.

Turning to Pl. 2 and following the construction of an egg chamber in detail: An egg plate (Ep, Fig. 1) is first made; a flap (FL) is cemented on; a flange (FG, Fig. 2) is next cemented around the outer edge of the egg plate; then a coverstrip (CVS) is attached; and a closing membrane (CM, Fig. 3) renders the plate ready for the eggs. This closing membrane is a membraneous flap of colleterial matter, thin and flexible, which is cemented all around its edge to the egg plate, except across the top; it bulges outwards from bottom to top, where it rests against the egg plate next added, and thus closes the exit from the chamber; but it is easily thrust back against the back plate of the chamber when the nymphs are squeezing their way out. The mode of junction of the egg plates is shown specially in Fig. 7, Pl. 2, and Fig. 5, Pl. 1, where the joints are purposely left not quite touching, as in some of the other figures, for the sake of clearness, but of course they are really closely cemented together. At Fig. 4, Pl. 2, is shown a side view of an egg plate, without the coverstrip; at Fig. 5, Pl. 2, three coverstrips cemented together. At Fig. 6, Pl. 2, a vertical section through an egg chamber on the line c-d, Fig. 7. At Fig. 7 three egg chambers are shown in plan, the single chamber projected from Fig. 6. In Fig. 6, $\mathrm{fl}^{2}$ is part of the flap of one of the chambers in the opposite row.

The shape of the flaps in transverse section is shown at UV, WX, YZ, Fig. 4, Pl. 1, representing sections across the flaps at about the heights of the corresponding lines in Fig. 3, Pl. 1. It will be seen that at $\mathrm{YZ}$ the flaps are joined or cemented together 
both at the ends and middles; at WX they are joined only at the ends; at UV they are altogether free. As the plates of the egg chambers in one row have flaps which are of equal breadth on either side of the longitudinal center of the ootheca, and as this is also the case with the chambers in the other row (which are half a chamber's depth behind or in advance) it follows that the flaps of the chambers on either side interlace. The lower edges of the two flaps forming an egg chamber are rigidly held on the outside of that row by two corresponding coverstrips; but the edge of the flap which comes across from the chamber of the opposite row and lies between the two former flaps is slightly within the full width and is left uncemented till a little lower down, and can thus be pushed slightly back by the emerging nymphs. Thus on each side of the row of flaps the lower edge of each flap is held rigidly or is semi-free alternately.

It may be added that some oothecæ are very small, having perhaps but six egg chambers; others have more than thirty, but the average length of an egg-case is about an inch, with about twentyfour chambers.

\section{EXPLANATION OF PLATE 8.}

\section{Figure 1.}

A, external side view, part of the exterior casing formed by the coverstrips broken away, exposing two egg chambers in the near row.

$B$, vertical section through longitudinal center.

$\mathrm{C}$, vertical section (on line $\mathrm{m}-\mathrm{n}$, Fig. 3) through two egg chambers in the far row.

$\mathrm{D}$, external side view of back end.

ec, egg chambers in far row.

ec, ${ }^{2}$ egg chambers in near row.

$\mathrm{cm}$, closing membrane.

Frgure 2 .

$A^{1}$, external top view.

cp, cover-plate.

$\mathrm{B}^{1}$, external top view, the flaps cut away as at UV.

$\mathrm{C}^{1}$, top view, outer casing removed, flaps cut away as at WX.

$\mathrm{D}^{1}$, top view, outer casing removed, flaps cut away as at $\mathrm{YZ}$.

$\mathrm{E}^{1}$, horizontal sections (on line $\mathrm{Q}-\mathrm{R}$, Fig. 3) through egg chambers.

e, last small plate forming rough chamber without eggs.

B, cover-plate. 


\section{Figure 3.}

Transverse view about the middle of the ootheca. The covering plate of the right-hand chamber removed. The flange, coverstrip and closing membrane not yet attached to the left-hand plate. The tips of the flaps are shown more or less straight up, instead of bent sharply forwards, as they are naturally.

$1,2,3$, etc., the eggs laid in the order of their numbers.

\section{Frgure 4.}

UV, section of flaps through line UV, Fig. 3.

WX, section of flaps through line WX, Fig. 3.

YZ, section of flaps through line YZ, Fig. 3.

\section{Figure 5.}

Horizontal section through egg chambers of the back end of the ootheca, about the line $Q-R$, Fig. 3. zz, ragged edges of egg plates, which sometimes project between the flanges.

In all the figures of this plate: $f g=$ flange; $f l=f l a p ; c r s=$ coverstrip; $\mathrm{ep}=$ egg plate; ec=egg chamber.

\section{EXPLANATION OF PLATE 9.}

Fig. 1, egg plate and flap cemented together.

Fig. 2, same, flange and coverstrip added.

Fig. 3, same, closing membrane added.

Fig. 4, same side view, but coverstrip not shown.

Fig. 5, three coverstrips cemented together.

\section{Figure 6.}

Vertical section through left-hand chamber, on line c-d, Fig. 7 .

$\mathrm{Fl}^{2}$, flap coming across from a right-hand chamber.

\section{FIgURE 7.}

Top view of three egg chambers, the upper part cut away about the line $a-b$, Fig. 6.

In all the figures of this plate: $\mathrm{ep}=\mathrm{egg}$ plate; $\mathrm{fl}=\mathrm{flap}$; $\mathrm{fg}=$ flange; $\mathrm{crs}=$ coverstrip $; \mathrm{cm}=$ closing membrane. 


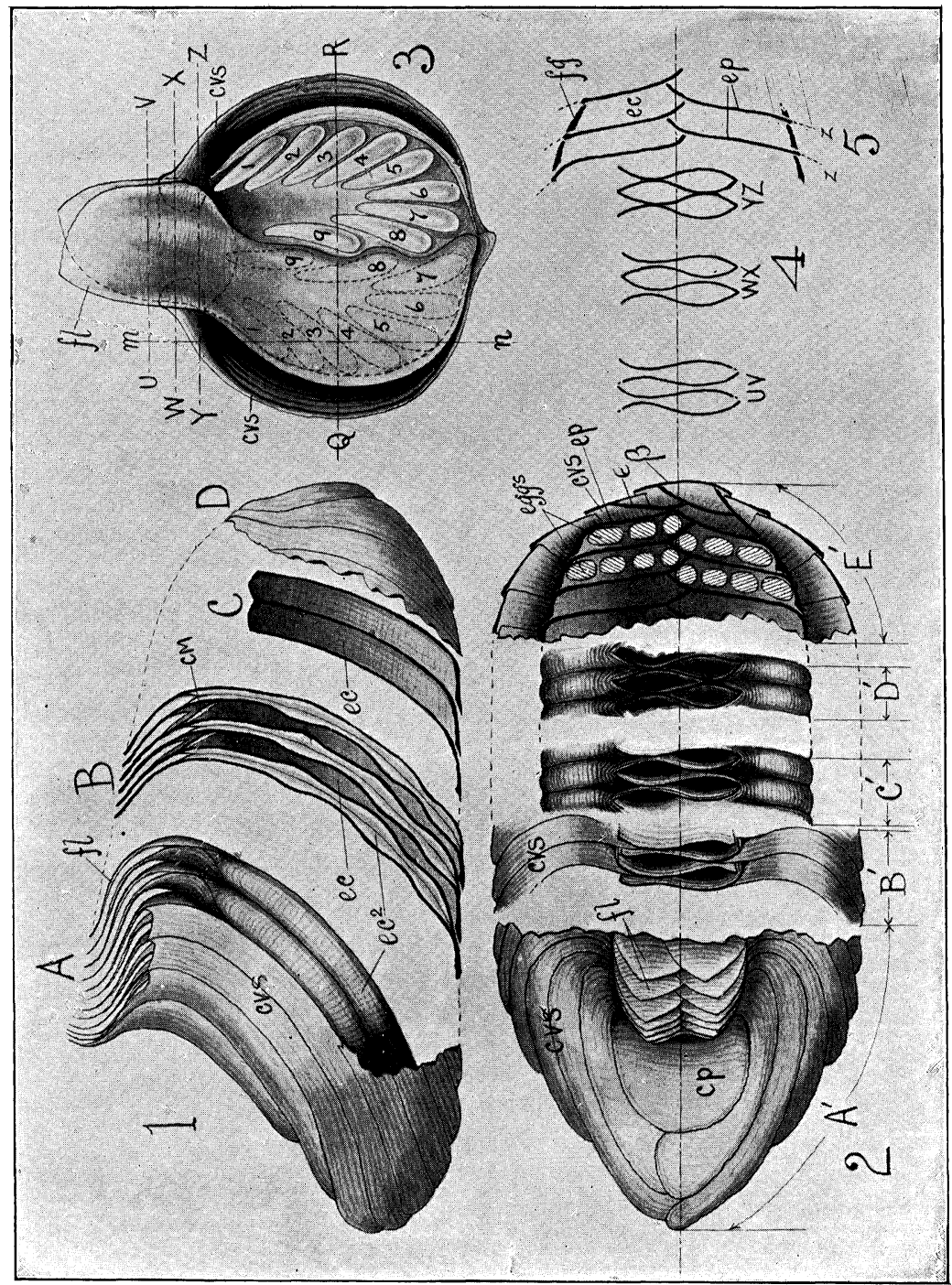

KERSHAW - OOTHECA OF HIERODULA SAUSSURII. 


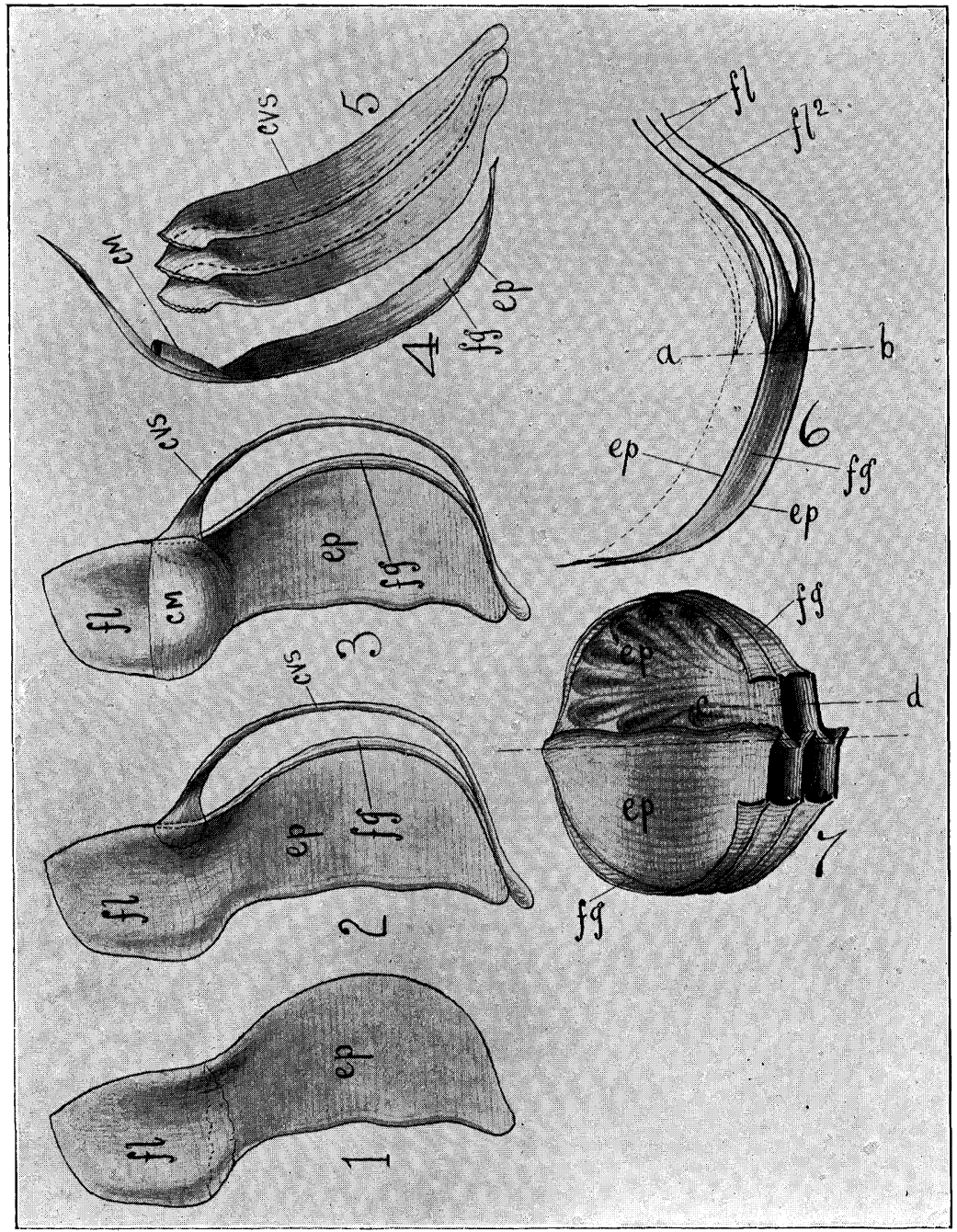

KERSHAW - OOTHECA OF HIERODULA SAUSSURII. 

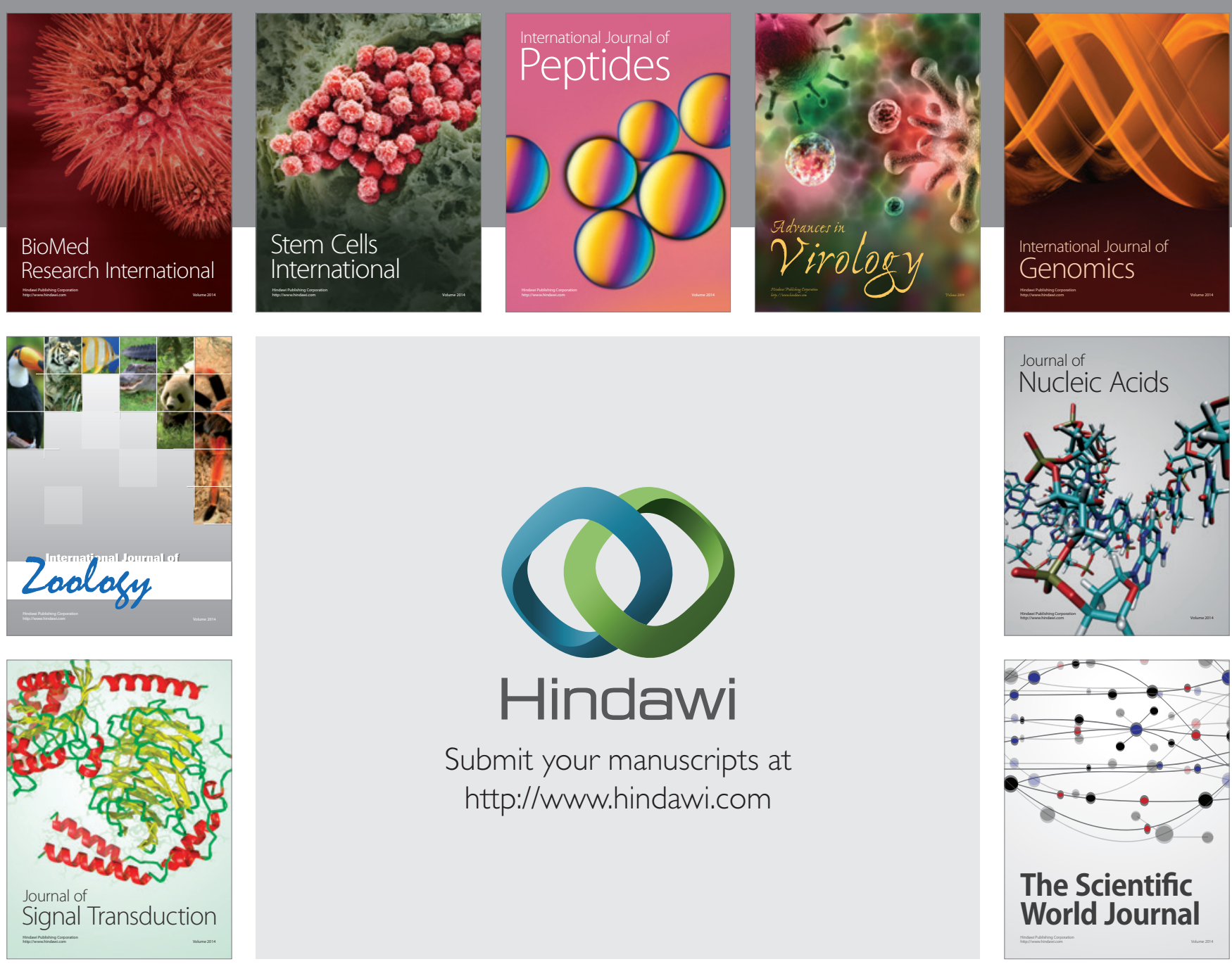

Submit your manuscripts at

http://www.hindawi.com
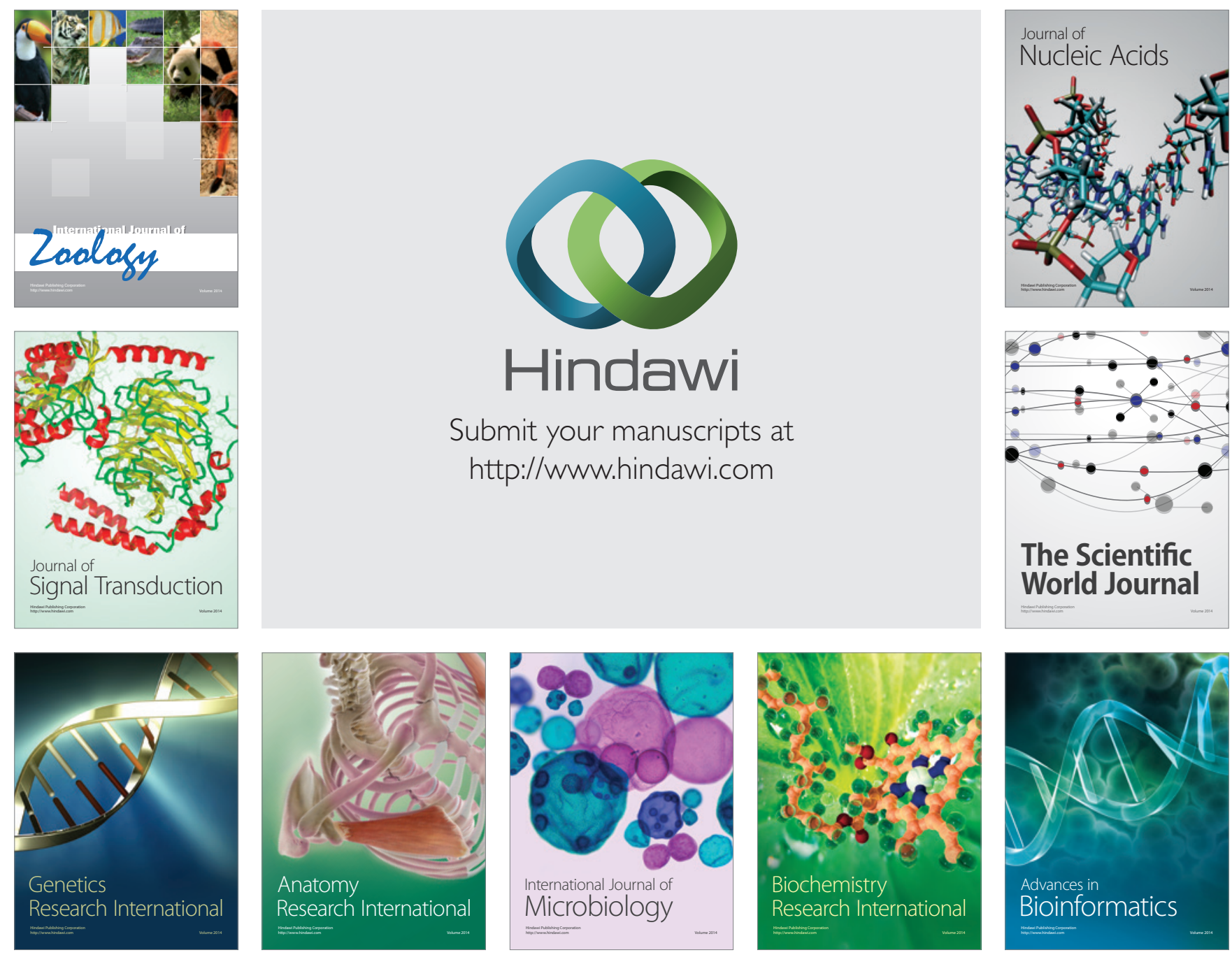

The Scientific World Journal
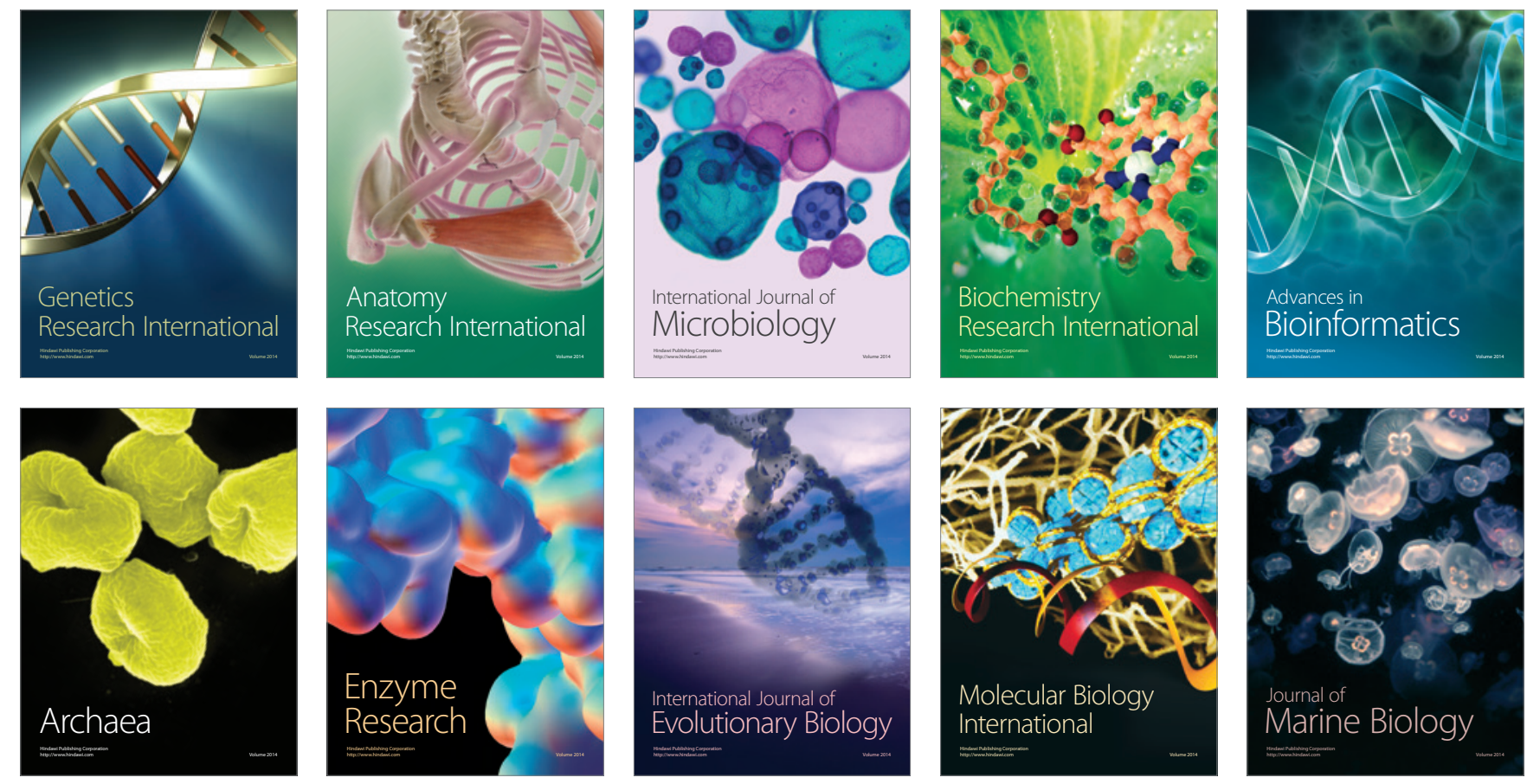